\title{
NOTA VOLANDERA A UNA RECETA DE APICIO
}

\begin{abstract}
Giarratano-Vollmer's surmise that the unsound reading baca in Apicius 3.ro.3 could conceal aqua, should not to be taken for granted on account of the implausibility of the transcription, the name of water being far too familiar to the scribes so as to mislead them in such a way. Instead, for the sake of palaeographical economy laca - a kind of brine-might be considered.
\end{abstract}

Enfrentado en funciones de censor ${ }^{1}$ con Apic. III 10.3 Aliter porros: in †baca coctos, ut supra, et inferes, me permití formular reservas sobre la pertinencia de limpiar la mácula precisamente con aqua ${ }^{2}$, a la par que iniciaba tímidos tanteos de amelioración. A mi entender, no falta fundamento para cuestionarla: fuera de que en lo que atañe al solo sentido no presenta ejecutorias de adhesión compulsiva (la cocción en agua se indica a continuación, cf. III 10.4, Aliter porros: 〈si in aquam elixati erunt...), a un vocablo tan común hay que concederle escasa exposición a las deformaciones de copista. Ensayaría ahora una nueva aproximación, por más que en ausencia de documentación aparenta menos hacedero el dar una en el clavo que ciento en la herradura.

$\mathrm{Si}$ en gracia a la economía paleográfica que ello comporta diéramos albergue provisional a la hipótesis de que los mss. llevaban en el punto en cuestión laca (y no marcha descarriada, claro es, la definición "nomen muriae cuiusdam", que para la única ocurrencia conocida del término [Ps. Theod. Prisc., add., p. 3r9.8 Rose] arbitra ThLL VII 2, 8r9.40), puede que la expresión in laca coctos admitiera ser entendida como una variación en el modo de preparación de los puerros, no me siento tentado a decir que insinuada pero al menos no desautorizada por pugnum salis de la primera de las cuatro entradas de que consta el capítulo (III Io.I Porros maturos fieri: pugnum salis, aquam et oleum mixtum

1 Cf. EMERITA 45, 1977, p. 190.

- Avanzada en la edición Giarratano-Vollmer, Leipzig, Teubner, 1922, y asumida por otras de tanta distinción como la reciente de J. André, Paris, Les Belles Lettres, r974. 
facies et ibi coques et eximes. Cum oleo, liquamine, mero et inferes). Bien que mis rudimentos de arte coquinaria no alcancen a ponderar con justeza las calidades del manjar así guisado, y menos todavía mis filologias a especular sobre su posible aceptación por los palata docta et erudita de la época, con todo la corrección que atisbo no me parece en principio empeorar el tenor del texto; y, por otra parte, es sobradamente sabido que no todas las recetas de la colección apiciana se destinaban a satisfacer las exigencias de gustos rebuscados. Se me ocurre; en cambio, apuntar sin mayores pretensiones que la utilización de una salmuera tal vez encontrara justificación desde el campo de la dietética: los tratadistas antiguos de medicina atribuían a los puerros,. entre otras, virtudes diuréticas $^{1}$, y acaso no sea de descartar sin más la posibilidad de que alguno del oficio diera en sospechar si no en descubrir empíricamente que la tal propiedad - real o imaginaria, en cualquier caso indeseable para consumo ordinario de estos vegetales - resultaba neutralizable por la acción del cloruro sódico.

Menor controvertibilidad afecta derivarse $-y$ vengo a rematar justo en el punto de partida- del hecho de que por ser laca voz de registro solitario en latín, su trivialización en baca daría mejor cuenta de la cosa transcripcional que la del nombre del agua.

Ramón Bai,Tar Veloso

Universidad de Santiago de Compostela

1 Cf. Cels. IV 17; Garg. Mart., Med. 21, p. 155.20 Rose; Cael. Aur., Chron. V 11.138. 